\title{
An Experimental Study on Disease Modeling for Mental Health
}

\author{
Biswadip Basu Mallik \\ Senior Assistant Professor in Mathematics Department of Basic Science and Humanities Institute of \\ Engineering \& Management, Kolkata West Bengal, India \\ Email: b.basumallik@gmail.com
}

\author{
Article Info \\ Page Number: 142 - 145 \\ Publication Issue:
}

Vol 71 No. 1 (2022)

\section{Article History}

Article Received: 18 November 2021

Revised: 03 December 2021

Accepted: 19 December 2021

Publication: 28 January 2022

\begin{abstract}
Mental health contributes significantly to people's capacity to uphold good physical health - mental illnesses, for instance, anxiety and depression the ability for people to engage in health-supporting manners. In the human services field, mental health embraces the interpersonal group experience and personal experience. Mental health refers to a condition of effective functioning of psychological purpose leading in productive activities, the ability to adjust to change and put up with challenges, and satisfying relations with people. Mental health is vital to interpersonal and family relationships, personal development, and the capacity to contribute to society.
\end{abstract}

Keywords: - Disease Modeling, Mental health etc.

\section{Introduction}

Human service workers need to understand the condition of the social systems, for instance, group, individual, society, individuals, community, and organization. The staff requires skills that assist them in understanding group dynamics, human development, the organization of cities, and organizational structure. Additionally, the workers need to know the set policy and different ways in which the social systems function in generating human problems. Most human services tasks demand direct contact with impaired individuals, thus susceptible to exploitation (Milner et al., 2019). Therefore, employers require to be selective during hiring and screening the applicants for the right credentials. Human services employees perform in collaboration with or under the supervision of other specialized staff. The employees working in the mental health section, for instance, may have the task of collaborating with a treatment team composed of psychologists, social workers, among other specialists. The level of supervision and degree of responsibility among the workers differ. Some employees handle the tasks alone and have minimal direct management, whereas others work under close supervision. This study focuses on the subject of mental health and its associated moderating factors in the human services field. 


\section{Methodology}

The focus of this study was in the association between mental illness and the character, intelligence, and willpower of an individual. Secondary data was collected from statistical outcomes reported in various journals and books, as well as institutional reports. Thus, with a focus being on both the qualitative and quantitative data, the study embraced inferential and descriptive statistical approaches before making inferences, as well as perceived valid and reliable conclusions. Also, the study selected the sources of data randomly. This decision sought to minimize potential bias while increasing the possibility of outcome generalization.

\section{Results and Discussion}

Public reaction to personal needs among the mentally ill persons triggers anticipated employment growth in residential care facilities and group homes. As more disabled persons lose their entitlement for services and programs issued by the public, it creates a demand for more community-based substitutes. Thus, there is a likelihood of increased pressure to react to the requirements of chronic mental patients. For a long time, due to deinstitutionalization, chronic psychiatric patients have had to stay at home. The movement to assist the mentally ill has resulted in a demand for the establishment of group residences and community-based programs. Thus, it creates a need for human services employees (Fekadu et al., 2019). The rise in employment opportunities in the social services field demands accurate screening of the candidates. Since the human services field deals with persons, it is essential to pay attention to the staff because it would be risking human lives.

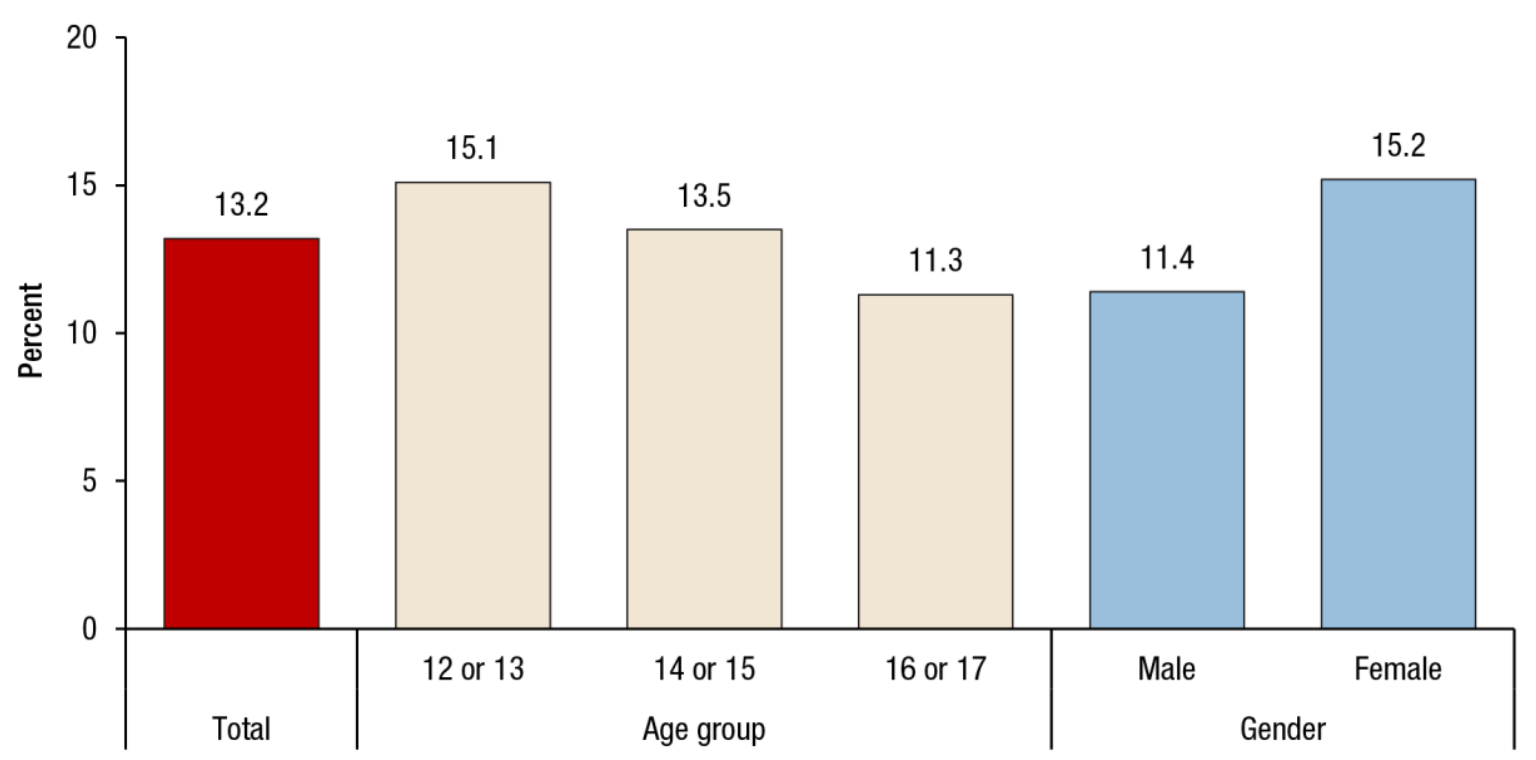

Severe Mental Illnesses (SMIs), mostly major depression, bipolar disorder, schizophrenia, are chronic conditions and deteriorate in nature, which may result in severe damage in different functional areas (Fekadu et al., 2019). SMIs reduce productivity and associate with excess mortality and high levels of physical illness comorbidity. The impacts of SMIs are noticeable in low/medium income nations where there is a tremendous difference in treatment for mental conditions. In such countries, family members take nearly all the accountability of handling the patients. People in the human services field may be prone to mental health because of the nature of their jobs. For instance, dealing with mentally challenged patients would require the 
staff to adapt to the various behaviors expressed by the patients. If a person formerly worked in the field and has mental health issues, the family would have to take the medical responsibility, which would become burdensome.

Mental health issues appear to be a very traumatic and painful time for families and influence the family's emotional and financial components. In most cases of mental illness, it is very likely to assume behavioral and emotional costs for members. Mental health conditions of individuals affect others in their social networks, mostly their families. Caring for a mentally ill family member can be stressful, and dealing with the stress may provoke various responses such as cognitive, somatic, behavioral, and emotional. Thus, mental health may affect human service clients because it might involve reducing social relations. The human services field is an area where people interact almost all the time.

Research shows that burnout is prevalent in the human services field, and public mental health considers it to be economically wasteful and costly, mainly due to the expense of training and recruiting staff. Researchers have empirically connected burnout with negative feelings concerning mental health clients. A study involving 510 psychiatric employees in 28 units discovered that increased levels of depersonalization and emotional exhaustion linked with negative attitudes, for instance, rejection towards clients (Morse et al., 2012). Negative staff attitudes relate to more unsatisfactory results among clients with a mental illness. A study empirically connecting burnout to poor customer satisfaction evaluated 333 mental health workers on 31 teams serving individuals with critical mental conditions, thus showing emotional exhaustion as the cause of burnout.

Mental health affects people in the human services field may affect their jobs resulting in early retirement. When the work gets out of hand, the workers fail to manage the clients, which becomes a negative factor. Also, mental health issues such as depression make the workers fail to focus on their jobs, which makes them unproductive entirely. The challenges faced on the job become challenging for the staff, and early retirement is the best solution for them to go and rest and have time to deal with their issues (Milner et. al., 2019). Other than that, sickness absence among the health service workers becomes one of the effects of mental health because the staff must go and seek help elsewhere. The lack slows down their work, making them record poor performance. Their caregivers might also advise them to stay away from work or stressful environments, and since human service involves interacting with people, the workers must remain under control.

\section{Conclusion}

In conclusion, mental health affects individuals in the human services field because they may seem less confident or affect their abilities. People may find it hard to concentrate or make decisions. The symptoms generated by mental illness may result in more significant thoughts. For instance, a person with low concentration in their work at the human service field may think since they have little attention, they cannot perform well in their job. Consequently, it affects their overall work performance because they feed themselves with negative thoughts. Additionally, it may tense their relationships with coworkers, clients, and supervisors due to low productivity. Affecting the abilities of people in the human services field would produce their products, which results in low output. 


\section{References}

[1].Fekadu, W., Mihiretu, A., Craig, T. K., \&Fekadu, A. (2019). Multidimensional impact of severe mental illness on family members: systematic review. BMJ Open, 9(12), e032391. https://doi.org/10.1136/bmjopen-2019-032391

[2].Milner, A., King, T. L., \& Kavanagh, A. (2019). The mental health impacts of health and human service work: Longitudinal evidence about differential exposure and susceptibility using 16 waves of cohort data. Preventive Medicine Reports, 14, 100826. https://doi.org/10.1016/j.pmedr.2019.100826

[3].Morse, G., Salyers, M. P., Rollins, A. L., Monroe-DeVita, M., \&Pfahler, C. (2011). Burnout in Mental Health Services: A Review of the Problem and Its Remediation. Administration and Policy in Mental Health and Mental Health Services Research, 39(5), 341-352. https://doi.org/10.1007/s10488-011-0352-1

[4].Olesen, S. C., Butterworth, P., Leach, L. S., Kelaher, M., \&Pirkis, J. (2013). Mental health affects future employment as job loss affects mental health: findings from a longitudinal population study. BMC Psychiatry, 13(1). https://doi.org/10.1186/1471-244x-13-144

[5].Jajoo, P. . "Understanding the Concept of Different Types of Web Crawling and Its Implementation". International Journal on Recent and Innovation Trends in Computing and Communication, vol. 9, no. 11, Nov. 2021, pp. 06-10, doi:10.17762/ijritcc.v9i11.5511.

[6].Dhabliya, M. D. . (2021). Cloud Computing Security Optimization via Algorithm Implementation. International Journal of New Practices in Management and Engineering, 10(01), 22-24. https://doi.org/10.17762/ijnpme.v10i01.99

[7].Zellar, P. I. . (2021). Business Security Design Improvement Using Digitization. International Journal of New Practices in Management and Engineering, 10(01), 19-21. https://doi.org/10.17762/ijnpme.v10i01.98 